DOI: $10.11649 /$ abs.2018.017

\author{
Zofia Sawaniewska-Mochowa \\ Instytut Slawistyki Polskiej Akademii Nauk \\ Warszawa \\ z.sawan@wp.pl
}

\title{
Nazwy wartości w językowym obrazie świata Litwinów
}

\author{
Recenzja
}

Kristina Rutkovska, Marius Smetona, Irena Smetonienè.

Vertybès lietuvio pasaulèvaizdyje [Wartości w językowym obrazie świata Litwina]. Monografija. Przedmowa w języku polskim i litewskim Jerzego Bartmińskiego. Vilnius: Vilniaus universiteto Filologijos fakultetas, Akademinè leidyba, 2017, 300 ss. ISBN 978-9955-33-715-7

Litewska etnolingwistyka jest dyscypliną stosunkowo młodą, ale już mającą zróżnicowany dorobek. Duże zasługi dla wypracowania odrębnego statusu badań etnolingwistycznych w obrębie litewskiego językoznawstwa miały prace Alojzasa Gudavičiusa (2009) i jego uczniów na temat związków języka z mentalnością narodu, jego cechami psychicznymi i kulturą duchową oraz studia frazeologiczno-leksykalne Birutė Jasiūnaitė (2010), głęboko osadzone w litewskiej kulturze narodowej, odwołujące się do sfery mitów, wyobrażeń, przesądów i obrzędów ludowych. Ten etap formowania się litewskiej refleksji etnolingwistycznej pozostawał koncepcyjnie pod silnym 
wpływem etnolingwistyki rosyjskiej w ujęciu Nikity Tołstoja, określanej przez Jerzego Bartmińskiego jako dialektologiczna i ukierunkowanej historycznie na kompleksowe badanie kodu kultury ludowej, przekazywanego za pomocą różnych środków, jak słowo, obrzęd, rytuał, rekwizyt, obraz (Bartmiński, 2016, ss. 8-9).

Nowy nurt w etnolingwistyce litewskiej wyznacza recenzowana monografia, napisana przez autorów z Wydziału Filologicznego Uniwersytetu Wileńskiego, Krystynę Rutkowską, Mariusa Smetonę i Irenę Smetonienè (Rutkovska, Smetona, \& Smetonienè, 2017). Prezentowany tom to wynik owocnej współpracy trzyosobowego zespołu litewskiego z etnolingwistami lubelskimi i badaczami z różnych krajów, przygotowującymi analizy nazw wartości do Leksykonu aksjologicznego Stowian i ich sąiadów (skrót LASiS) w ramach międzynarodowego konwersatorium EUROJOS. Zetknięcie się z instrumentarium językowego obrazu świata i metodologią aksjolingwistyki (badania języka w kontekście wartości) okazało się dla językoznawców litewskich inspirujące i odkrywcze, wkroczyli bowiem z powodzeniem w obszary badań dotychczas w językoznawstwie litewskim nieobecne, problematykę teorii semantyki językowej i lingwistyki antropologiczno-kulturowej w ujęciu zachodnim. Wydana monografia zawiera charakterystyki semantyczne sześciu kluczowych pojęć aksjologicznych w języku litewskim, przygotowane przez wymienionych autorów do kolejnych tomów LASiS, w recenzowanej pracy przedstawione w wersji litewskojęzycznej. Nazwy poszczególnych wartości opracowali: NAMAI (DOM) i ŠEIMA (RODZINA) Krystyna Rutkowska; DARBAS (PRACA) - Krystyna Rutkowska, Marius Smetona, Irena Smetoniene; EUROPA - Marius Smetona; LAISVÉ (WOLNOŚĆ) i GARBÉ (HONOR) - Irena Smetonienė. Powyższe artykuły poprzedzają analizy semantyczne dwóch nowych konceptów, pojęć związanych z pojmowaniem pierwszych elementów świata przez człowieka, takich jak UGNIS (OGIEŃ) i VANDUO (WODA), opracowane przez Mariusa Smetonę.

Rozumienie nazw wartości przez różne narody nieprzypadkowo stało się w obecnej, dynamicznie zmieniającej się rzeczywistości, centralnym zagadnieniem badawczym etnolingwistyki ukierunkowanej aksjologicznie. O ile pojęcia kosmologiczne, jak OGIEN czy WODA, będące archetypami, mają w wielu językach i kulturach trwałą pojemność znaczeniową, o tyle semantyka i hierarchizowanie takich kluczowych wartości, jak WOLNOŚĆ, DOM, RODZINA, PRACA, HONOR czy EUROPA mogą się zmieniać, gdy ludzie w sytuacjach konfliktów zbrojnych i kataklizmów doświadczają na dużą skalę zagrożenia życia, bezdomności, utraty bliskich, ograniczania wolności wyboru, gdy narasta fala krytycyzmu wobec Unii Europejskiej.

Oprócz zasadniczej części empiryczno-analitycznej książka zawiera przedmowę Jerzego Bartmińskiego, twórcy lubelskiej etnolingwistyki (por. Bartmiński, 2009, ss. 40-50) i światowej sławy uczonego, w dwóch wersjach językowych, polskiej i litewskiej, co jest bardzo dobrym rozwiązaniem, bo zwiększa się tym samym krąg potencjalnych odbiorców i ranga publikacji jako ważnego opracowania etnolingwistycznego. 
Badacz w krótkim, ale jakże esencjonalnym tekście, tłumaczy potrzebę badania semantyki nazw wartości i mocno podkreśla, że dociekaniom aksjolingwistycznym musi towarzyszyć świadomość, iż wartości we współczesnym świecie są poddawane relatywizacji kulturowej, manipulacji, presji światopoglądowej i politycznej (Bartmiński, 2017b, s. 11).

Cennym uzupełnieniem zawartości monografii jest także przedmowa otwierająca książkę, napisana przez troje autorów, wyjaśniająca powody jej powstania, ze szczególnym podkreśleniem znaczenia współpracy badaczy litewskich ze środowiskiem pomysłodawców i twórców LASiS. Wskazane też zostały tutaj ważniejsze artykuły i studia litewskich autorów, poprzedzające opracowanie monografii (Rutkovska, 2016; Rutkovska \& Smetona, 2016; Smetona, 2016; Smetona, \& Smetoniené, 2016; Smetonienè, 2015a, 2015b, 2016). Właściwe charakterystyki nazw wartości poprzedza rozdział wstępny, przedstawiający syntetycznie podstawy teoretyczne badań etnolingwistycznych (a zwłaszcza koncepcję językowego obrazu świata) oraz główne ukierunkowania i etapy w rozwoju tej subdyscypliny lingwistyki (z uwzględnieniem stanu badań na Litwie). W tej części pracy znalazło się również szczegółowe omówienie przyjętych metod gromadzenia materiału i sposobów analizy wybranych nazw wartości w językowym obrazie świata Litwinów. Całości dopełnia podsumowanie, obszerne streszczenie w języku angielskim, wykaz przyjętych skrótów i źródeł (w tym aż 43 witryny internetowe, $\mathrm{z}$ których czerpano materiał).

Konsekwencja w zastosowaniu jednorodnej metodologii opisu pojęć aksjologicznych, wypracowanej zespołowo na potrzeby LASiS, przyniosła, w przypadku opracowania autorów litewskich, bardzo dobre efekty, podkreślone również w przedmowie przez Jerzego Bartmińskiego. Powstała monografia rzetelna, warsztatowo spójna, oparta na bogatej bazie materiałowej, historycznej i współczesnej, obejmującej trzy typy danych: systemowe, tekstowe i ankietowe oraz uwzględniającej funkcjonowanie nazw wartości w różnych typach dyskursów (poczynając od literackiego przez specjalistyczne, publicystyczne po internetowy). W kontekście gromadzenia danych materiałowych sugerowałabym może jedynie szersze wykorzystywanie w analizach nazw wartości tekstów kultury popularnej (piosenek, przekazów satyrycznych, różnych wytworów street artu, spajających kod werbalny z wizualnym), w których również odzwierciedlają się ciekawe językowe reprezentacje pojęć wartościujących, takich jak np. WOLNOŚĆ, PATRIOTYZM czY NARÓD.

Precyzja metodyczna, z jaką skonstruowane zostały przez autorów litewskich opisy poszczególnych nazw wartości, zwieńczone wypracowaniem definicji kognitywnych, pozwala na ich porównywanie $\mathrm{z}$ opracowanymi w podobny sposób tymi samymi pojęciami wartościującymi na materiale innych języków. Na dwa sposoby prowadzenia badań komparatystycznych nad konceptualizacją nazw wartości w różnych językach, z wykorzystaniem do porównań konceptów prezentowanych w monografii litewskiej, wskazuje J. Bartmiński w zakończeniu przywoływanej już wcześniej przedmowy: 
Można porównywać - najczęściej - jakiś jeden język z jakimś jednym innym językiem, zwykle przy tym uprzywilejowując język mający pozycję mocniejszą, język światowy. Ale można zejść na poziom bardziej podstawowy, wedle założonego porządku opracować paralelne opisy różnych języków i dać potencjalnym czytelnikom języków podstawowe narzędzia do konfrontacji selektywnej, obejmującej różne dowolnie zestawiane języki. Opisy przygotowane przez autorów litewskich [...] wpisują się w ten drugi scenariusz (Bartmiński, 2017b, s. 13).

Ramy tej z konieczności krótkiej recenzji nie pozwalają mi na dokonanie przeglądu charakterystyk semantycznych pojęć, przygotowanych przez badaczy litewskich, i wskazanie w tych językowych konceptualizacjach nazw wartości cech dominujących i peryferyjnych oraz wyłonionych profilów. Niech niedosyt poznawczy, jakiego z tego powodu doświadczy czytelnik, stanie się zachętą do sięgnięcia po wydane już trzy tomy Leksykonu aksjologicznego Słowian i ich sąsiadów (Bartmiński, 2017a; Bartmiński, Bielińska-Gardziel, \& Niebrzegowska-Bartmińska, 2015; Bartmiński, Brzozowska, \& Niebrzegowska-Bartmińska, 2016), w których prezentowane są paralelne opisy pojęć DOM, PRACA i HONOR na materiale litewskim i innych języków (w druku tomy LASiS poświęcone konceptowi EUROPY i WOLNOŚCI), a odbiorców litewskich, nawet jeśli są sceptycznie nastawieni do warsztatu etnolingwistyki kognitywnej i instrumentarium językowego obrazu świata, skłoni do przestudiowania recenzowanej książki, by poznać obraz świata wartości, jaki mają w głowach Litwini, a przez to może lepiej zrozumieć siebie i innych.

Jedna jeszcze na koniec refleksja, jaką wyniosłam z lektury tego starannie przygotowanego opracowania. Językowy obraz wartości Litwinów warto zestawiać w różnych aspektach z polskim obrazem pojęć aksjologicznych na zasadzie równorzędności języków i wyciągać wnioski na temat zbieżności i różnic. Może takie głębokie wnikanie w naszą mentalność ułatwi budowanie mostów porozumienia między oboma narodami sąsiedzkimi, różniącymi się nierzadko w ocenie przeszłości i konstruowaniu pamięci historycznej, ale bliskimi sobie w konceptualizacji kluczowych wartości, takich jak WOLNOŚĆ, DOM, RODZINA, EUROPA czy HONOR.

\section{Bibliografia}

Bartmiński, J. (2009). Lubelska etnolingwistyka. W J. Bartmiński, Stereotypy mieszkaja w języku: Studia etnolingwistyczne (ss. 40-50). Lublin: Wydawnictwo Uniwersytetu Marii Curie-Skłodowskiej.

Bartmiński, J. (2016). O aktualnych zadaniach etnolingwistyki. Etnolingwistyka, 28, 7-29.

Bartmiński, J. (Red.). (2017a). Leksykon aksjologiczny Słowian i ich sąsiadów [LASiS]: T. 5. HONOR. Lublin: Wydawnictwo Uniwersytetu Marii Curie-Skłodowskiej. 
Bartmiński, J. (2017b). Przedmowa. W K. Rutkovska, M. Smetona, \& I. Smetonienè, Vertybės lietuvio pasaulevaizdyje: Monografija (ss. 11-13). Vilnius: Vilniaus universiteto Filologijos fakultetas, Akademinè leidyba.

Bartmiński, J., Bielińska-Gardziel, I., \& Niebrzegowska-Bartmińska, S. (Red.). (2015). Leksykon aksjologiczny Słowian i ich sąsiadów [LASiS]: T. 1. DOM. Lublin: Wydawnictwo Uniwersytetu Marii Curie-Skłodowskiej.

Bartmiński, J., Brzozowska, M., \& Niebrzegowska-Bartmińska, S. (Red.). (2016). Leksykon aksjologiczny Słowian i ich sasiadów [LASiS]: T. 3. PRACA. Lublin: Wydawnictwo Uniwersytetu Marii Curie-Skłodowskiej.

Gudavičius, A. (2009). Etnolingvistika: Tauta kalboje. Šiauliai: Šiaulių universiteto leidykla.

Jasiūnaitè, B. (2010). Šventieji ir nelabieji frazeologijoje ir liaudies kultūroje. Vilnius: Vilniaus universiteto leidykla.

Rutkovska, K. (2016). Namų konceptas lietuvių kalboje ir kultūroje. Lietuvių kalba, 2016(10), 1-31. Pobrano 1 października 2018, z http://www.lietuviukalba.lt/index.php/lietuviukalba/article/view/207/164

Rutkovska, K., \& Smetona, M. (2016). Kultūra kalboje. Vilnius: Vilniaus universiteto leidykla. Pobrano z https://www.flf.vu.lt/mokslas/elektroniniai-istekliai\#vadoveliai-mokymopriemones

Rutkovska, K., Smetona, M., \& Smetonienè, I. (2017). Vertybès lietuvio pasaulèvaizdyje: Monografija. Vilnius: Vilniaus universiteto Filologijos fakultetas, Akademinė leidyba.

Smetona, M. (2016). Europos samprata lietuvio sąmoneje. Parlamento studijos: Mokslo darbai, 2016(20), 133-157.

Smetona, M., \& Smetonienè, I. (2016). DARBAS (PRACA) w niektórych dyskursach litewskich. Etnolingwistyka, 28, 101-116.

Smetonienè, I. (2015a). GARBĖS koncepto analizè. Filologija, 2015(20), 62-74.

Smetonienè, I. (2015b). Lituviška garbès samprata. Parlamento studijos: Mokslo darbai, 2015(18), 63-83.

Smetonienè, I. (2016). Is honor still important for Lithuanians? Lituanus, 62(1), 23-39. 


\title{
Nazwy wartości w językowym obrazie świata Litwinów
}

\author{
Recenzja \\ Kristina Rutkovska, Marius Smetona, Irena Smetonienè. Vertybès \\ lietuvio pasaulèvaizdyje. Monografija [Wartości w językowym obrazie \\ świata Litwina. Monografia]. Przedmowa w języku polskim i litewskim \\ Jerzego Bartmińskiego. Vilnius: Vilniaus universiteto Filologijos \\ fakultetas, Akademinè leidyba, 2017, 300 ss. ISBN 978-9955-33-715-7
}

\section{Streszczenie}

Litewska etnolingwistyka jest dyscypliną młodą. W 2017 roku wzbogaciła się o cenną monografię napisaną przez troje badaczy z Uniwersytetu Wileńskiego, Krystynę Rutkowską, Mariusa Smetonę i Irenę Smetonienė, uczestników międzynarodowego projektu EUROJOS, współpracujących przy tworzeniu Leksykonu aksjologicznego Słowian i ich sąsiadów.

Opracowanie pod tytułem Vertybès lietuvio pasaulevaizdyje [Wartości w językowym obrazie świata Litwina], z przedmową Jerzego Bartmińskiego, zawiera pełne charakterystyki semantyczne sześciu kluczowych nazw wartości (konceptów): DOMU, RODZINY, PRACY, EUROPY, WOLNOŚCI i HONORU oraz dwóch pojęć, WODY i OGNIA, sięgających najbardziej archaicznych źródeł kultury ludzkiej.

Słowa kluczowe: etnolingwistyka; język litewski; językowy obraz świata; nazwy wartości (koncepty): DOM, RODZINA, PRACA, EUROPA, WOLNOŚĆ, HONOR; pojęcia kosmiczne: WODA, OGIEŃ 


\title{
The names of values in the linguistic worldview of Lithuanians
}

\author{
Review \\ Kristina Rutkovska, Marius Smetona, Irena Smetonienè. Vertybès \\ lietuvio pasaulevaizdyje. Monografija [Values in the linguistic worldview \\ of Lithuanians: A monograph]. Foreword in Polish and Lithuanian by \\ Jerzy Bartmiński. Vilnius: Vilniaus universiteto Filologijos fakultetas, \\ Akademinè leidyba, 2017, 300 pp. ISBN 978-9955-33-715-7
}

\begin{abstract}
Lithuanian ethnolinguistics is a relatively young discipline. In 2017, it was enriched by a valuable monograph written by three researchers from Vilnius University: Kristina Rutkovska, Marius Smetona and Irena Smetonienè, participants in the international project EUROJOS, who have made a significant contribution to the Leksykon aksjologiczny Słowian i ich sasiadów (Axiological lexicon of the Slavs and their neighbours).

Their study entitled Vertybés lietuvio pasaulevaizdyje (Values in the linguistic worldview of Lithuanians), with a foreword by Jerzy Bartmiński, offers a full semantic description of six key names of values (concepts): HOME, FAMILY, WORK, EUROPE, FREEDOM and HONOUR. It also analyses two concepts stemming from the most archaic sources of human culture: FIRE and WATER.
\end{abstract}

Keywords: ethnolinguistics; Lithuanian language; linguistic worldview; names of values (concepts): HOME, FAMILY, WORK, EUROPE, FREEDOM, HONOUR; cosmic concepts: FIRE, WATER

Dr hab. Zofia Sawaniewska-Mochowa, Associate Professor at the Institute of Slavic Studies of the Polish Academy of Sciences, Warsaw; PhD - 1986, University of Warsaw; habilitation in Slavic Linguistics - 2003, Institute of Slavic Studies; author of two books, over seventy scholarly articles, essays and reviews; co-author of two books and a dictionary; co-editor of four collective volumes. She has conducted extensive research on the linguistic and cultural heritage of gentry in the former Grand Duchy of Lithuania. She has worked in Lithuanian archives researching manuscripts, letters and memoirs; she also studies manuscripts of the nineteenth-century translational dictionaries; her scholarly interests include dialectology, local dialects and regional 
varieties of Polish, the sociolect of the descendants of Lithuanian gentry, history and language of the former North-Eastern Borderlands of Poland (contemporary territory of Lithuania), sociolinguistics and ethnolinguistics.

Bibliography (selected): Poradnik Jana Karłowicza jako źródło poznania potocznej polszczyzny pótnocnokresowej. Słownictwo [Jan Karłowicz's manual as a source for description of the colloquial Polish in the North-Eastern Borderlands of Poland: Vocabulary], Warszawa (Warsaw) 1990; Ze studiów nad socjolektem drobnej szlachty kowieńskiej XIX wieku (na podstawie słowników przekładowych Antoniego Juszkiewicza) [From studies of the 19th century Kaunas District yeomanry sociolect (based on Antoni Juszkiewicz's translational dictionaries)], Bydgoszcz 2002; (with Anna Zielińska), Dziedzictwo kultury szlacheckiej na bytych Kresach pótnocno-wschodnich Rzeczypospolitej. Ginaca część kultury europejskiej [The heritage of gentry culture in the former Grand Duchy of Lithuania: A vestigial aspect of European culture on the verge of total extinction], Warszawa (Warsaw) 2007.

Correspondence: Zofia Sawaniewska-Mochowa, Institute of Slavic Studies, Polish Academy of Sciences, Warsaw, e-mail: z.sawan@wp.pl

Support of the work: The study was conducted at the author's own expense.

Competing interests: The author is the Editor-in-Chief of this journal. 